\title{
Control System for Dichlorophenol and Volatile Organic Compound Catalytic Reduction Performance Analysis
}

\author{
Ming-Sen $\mathrm{Hu}^{*}$ and Liang-Hsiu Chen ${ }^{1}$ \\ Department of Aviation \& Communication Electronics, Air Force Institute of Technology, \\ No. 198, Jieshou West Road, Gang-Shan District, Kaohsiung City 820, Taiwan, R.O.C. \\ ${ }^{1}$ Department of Translation and Interpretation Studies, Chang Jung Christian University, \\ No. 1, Changda Road, Gueiren District, Tainan City 711, Taiwan, R.O.C.
}

(Received April 20, 2017; accepted October 24, 2017)

Keywords: catalytic reduction, automatic measurement, automatic control, software development, system integration

In this paper, we present an automatic monitoring system for an industrial catalytic reduction method to deal with the needs in the analysis of the efficiency of emissions of dichlorophenol and volatile organic compounds (VOCs). The system uses automatic measurement, control, and hardware and software design techniques. This allows the user to set the control parameters for the catalytic reaction as required and to perform monitoring procedures for the reduction reaction of dichlorophenol and VOC catalyst. The system can control the flow of the participating gas and the evaporator temperature for the mixing of gases and dichlorophenol or VOC mixture, and then send it to the catalyst bed for three-stage temperature-monitoring operations. At the same time, the system can automatically record the information related to the catalytic reaction process and establish an analysis curve to be used as the basis for analyzing the reduction efficiency of the dichlorophenol and VOC catalyst.

\section{Introduction}

Because of the vigorous development of modern industry, transportation, and the prevalence of tobacco products, large amounts of dichlorophenol (also known as 2,4-dichlorophenol) and volatile organic compounds (VOCs) are being generated. ${ }^{(1,2)}$ Moreover, paints, coatings, adhesives, decorative materials, furniture, household appliances, and cleaning agents all contain these VOCs. Dichlorophenol and VOCs will cause not only smog and air pollution, but also all kinds of harm to the human body in the long run when we are exposed to these in the environment. ${ }^{(1,3)}$ Residues of these materials in the soil or water will result in soil and groundwater contamination. When stored in the atmosphere, they will react with sunlight and nitrogen dioxide $\left(\mathrm{NO}_{2}\right)$ in photochemical reactions to form ozone, causing global warming and damage to the growth of crops.

At present, the main method for the treatment of dichlorophenol and VOCs in industry is the use of selective catalytic reduction (SCR), ${ }^{(4-8)}$ which converts dichlorophenol and VOCs into a harmless gas that can be discharged into the atmosphere, in order to reduce the harm caused by dichlorophenol and VOCs. Catalytic reduction varies with different concentrations or proportions of nitrogen $\left(\mathrm{N}_{2}\right)$, methyl $\left(\mathrm{CH}_{2}\right)$, sulfur dioxide $\left(\mathrm{SO}_{2}\right)$, the air in general (air) and other gases, and

*Corresponding author: e-mail: mshu1227@gmail.com

http://dx.doi.org/10.18494/SAM.2017.1704 
dichlorophenol or VOCs, forming a mixture of gases that undergo catalytic reaction. At the same time, the performance of catalytic reduction are closely related to temperature. ${ }^{(9-13)}$ At present, the performance analysis of catalytic reduction must rely on manual methods. Although the complex multistage temperature control and data logging operations are both costly in terms of manpower and material resources, they provide insufficient accuracy.

To effectively analyze the performance of the catalytic reduction of dichlorophenol and VOC mixed gases, ${ }^{(14-16)}$ a set of monitoring and control systems for dichlorophenol and VOC catalyst performance are developed in this study. Users can set various flow parameters and control parameters for the catalytic reaction. The flow rate parameters can be used to tailor the desired concentration of dichlorophenol or VOCs. The control parameters can be used to monitor the reaction of the dichlorophenol or VOC catalyst, and then, the system automatically records all the reaction process data and establishes a catalytic reduction curve to be used as the basis for performance analysis.

\section{Materials and Methods}

The structure of the monitoring and control system of dichlorophenol and VOC catalytic reactions developed in this study is shown in Fig. 1, and its components and functions are described as follows.

(1) Nitrogen input device: introduces a flow of nitrogen into the evaporator.

(2) Dichlorophenol evaporator: nitrogen is evaporated by heating with dichlorophenol and evaporated dichlorophenol is delivered to the first mixer.

(3) First VOC evaporator: nitrogen is evaporated by heating with the first VOC, and evaporated VOC is transported to the second mixer.

(4) Second VOC evaporator: nitrogen is evaporated by heating with the second VOC, and evaporated VOCs are transported to the second mixer.

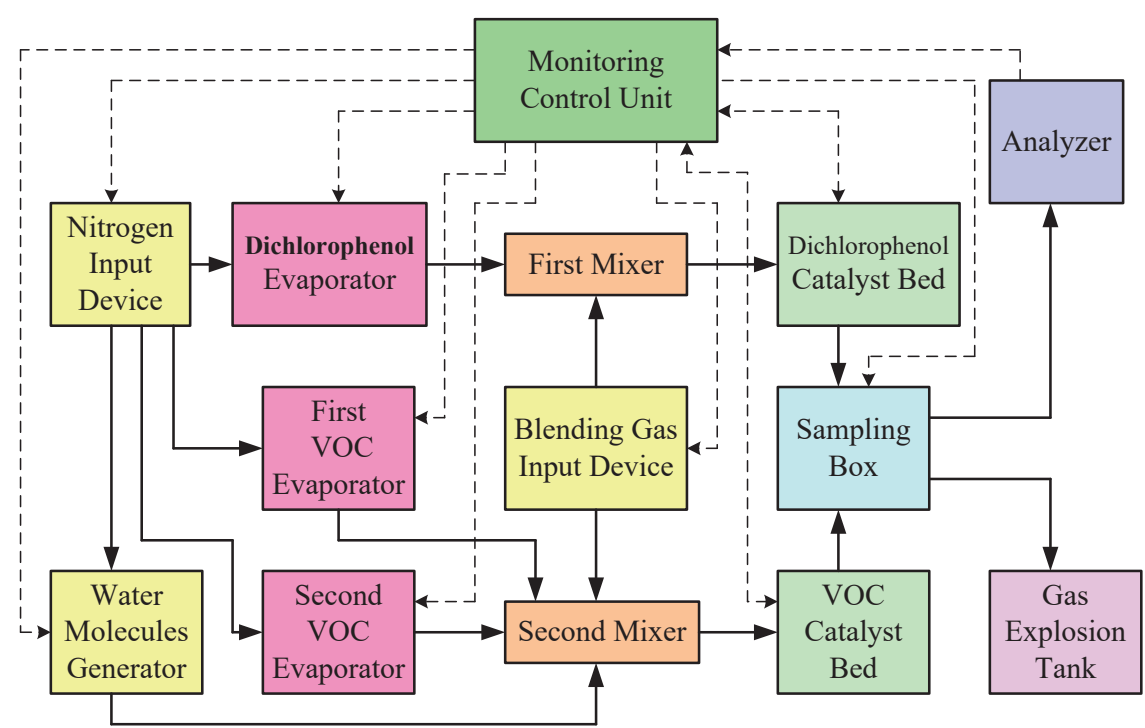

Fig. 1. (Color online) Catalyst performance analysis monitoring system architecture. 
(5) Blending gas input device: contains $\mathrm{CH}_{2}, \mathrm{SO}_{2}$, air, and other blending gases. Following the specified flow, a variety of gases are input into the corresponding mixer.

(6) Water molecule generator: with the input of nitrogen and water molecules, a designated flow is delivered to the second mixer.

(7) First mixer: dichlorophenol is uniformly mixed with nitrogen and air, forming a dichlorophenol mixed gas that is delivered to the dichlorophenol catalyst bed.

(8) Second mixer: VOCs, nitrogen, blending gases, and water molecules are uniformly mixed to form a VOC mixed gas that is delivered to the VOC catalyst bed.

(9) Dichlorophenol catalyst bed: dichlorophenol mixed gases are preheated or used in the catalytic reaction, and then, the warmed gases or dichlorophenol mixed gas after catalytic reaction is delivered to the sampling box.

(10) VOC catalyst bed: VOC mixed gas is preheated or subjected to catalytic reaction, and then, the warmed gas or VOC gas mixture is transported to the sampling box.

(11) Sampling box: dichlorophenol mixed gas or VOC mixed gas sampling shunt, controls dichlorophenol mixed gas or VOC gas mixture for analysis or input to gas explosion tank.

(12) Analyzer: analyzes dichlorophenol or VOC concentrations.

(13) Gas explosion tank: After the use of chemicals to adsorb dichlorophenol or VOCs for exclusion.

(14) Monitoring control unit: the monitoring software for this unit is developed in LabVIEW graphical language ${ }^{(17)}$ and provides the following functions: (a) adjusting the flows of nitrogen input device, blending gas input devices, and water molecule generator, (b) monitoring the evaporation temperatures of the dichlorophenol and the VOC evaporator, (c) controlling the catalyst conversion of the dichlorophenol catalyst bed and the VOC catalyst bed, (d) controlling the gas flow into the sampling chamber to analyze the results or into the gas slot groove for exclusion, and finally, (e) recording the data related to the catalytic reaction process automatically and formulating the analysis curves needed.

The dichlorophenol and VOC catalyst performance analysis monitoring system hardware design of the Process and Instrument Diagram (P \& ID) is shown in Fig. 2(a) below. In the figure, MIX \#1 and MIX \#2 represent the first mixer that is capable of producing a mixed gas of dichlorophenol and the second mixer that is capable of generating a VOC mixed gas, respectively. The gray area is a sampling box for sampling the mixture of the dichlorophenol mixed gas and the VOC mixed gas. The symbol appearing as a boxed circle indicates a sensing element that can transmit the measurement signal to the monitoring control unit. In this study, the monitoring and control system for the performance of the dichlorophenol and VOC catalysts was developed and manufactured. The entire system is shown in Fig. 2(b).

\section{Monitoring Parameter Settings}

In this study, we focused on monitoring the performance of dichlorophenol and VOC catalysts. Before carrying out the catalytic reaction of dichlorophenol or VOCs, the user must first set the monitoring parameters on the parameter-setting screen shown in Fig. 3, such that the flow rates of each blending gas are parameters 1 to 8 , the three-stage temperature control parameters of the dichlorophenol catalyst bed are parameters 9 to 14 , and the VOC catalyst bed three-stage temperature control parameters are parameters 15 to 20 , as well as setting the evaporator, mixer, and sampling box temperatures. The flow rate of the reference gas can determine the concentration 


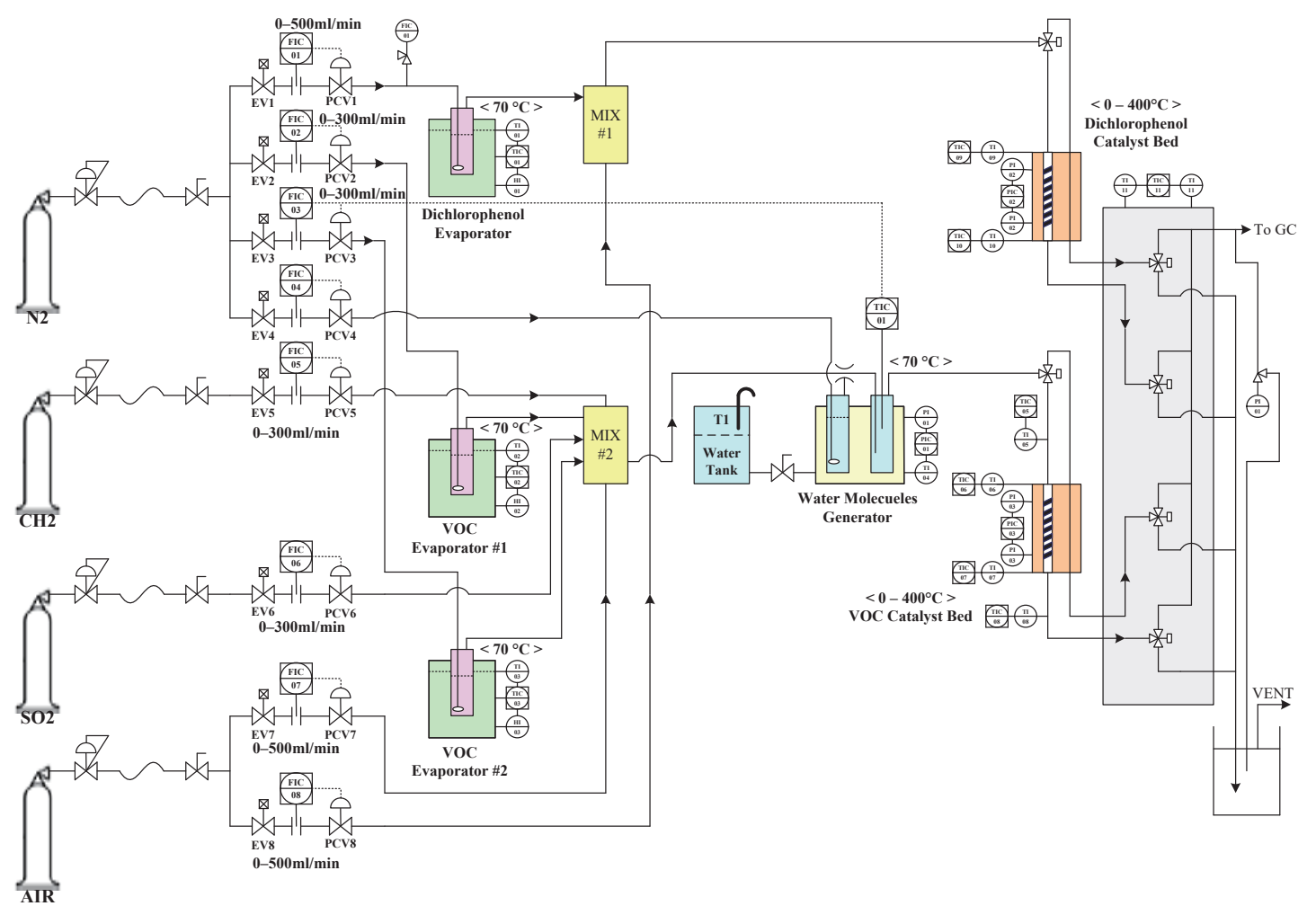

(a)

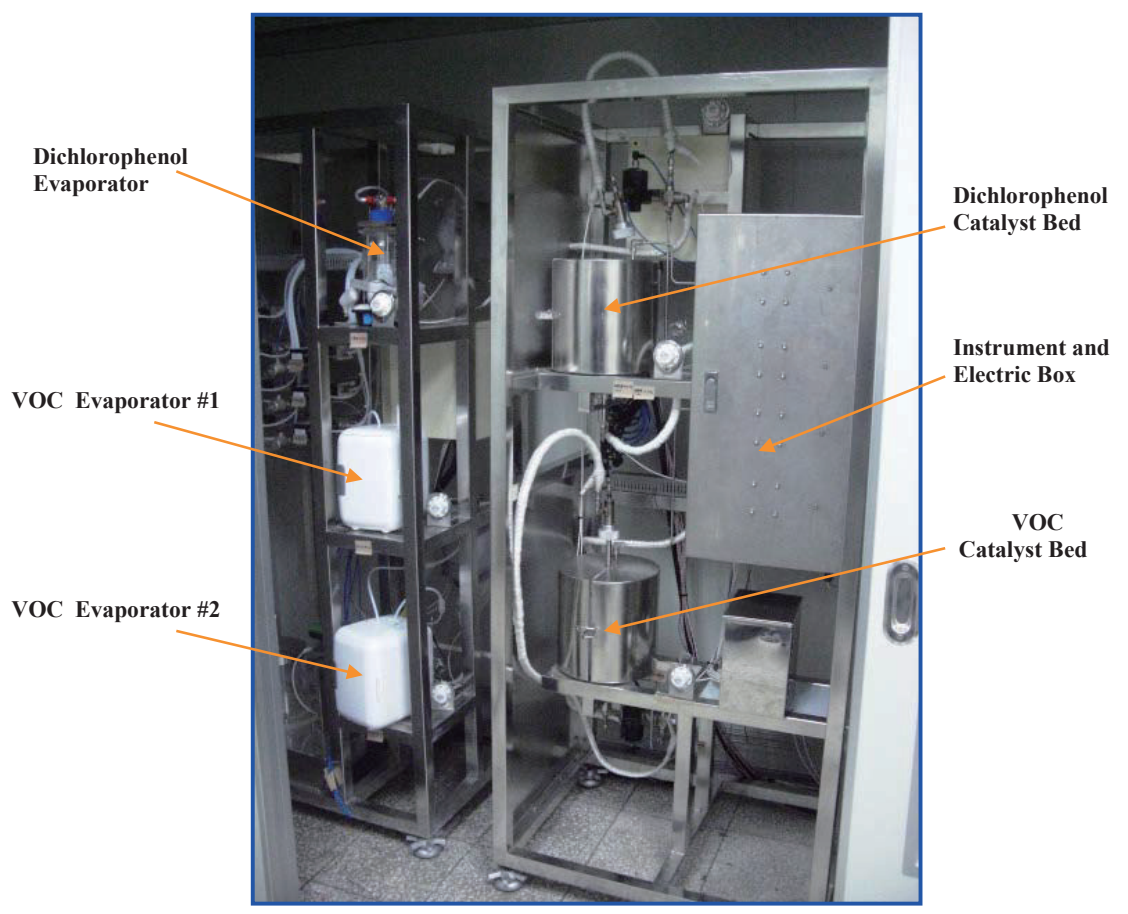

(b)

Fig. 2. (Color online) Hardware design of catalyst performance analysis monitoring system. (a) Hardware design of P \& ID. (b) Entire catalyst performance analysis monitoring system. 


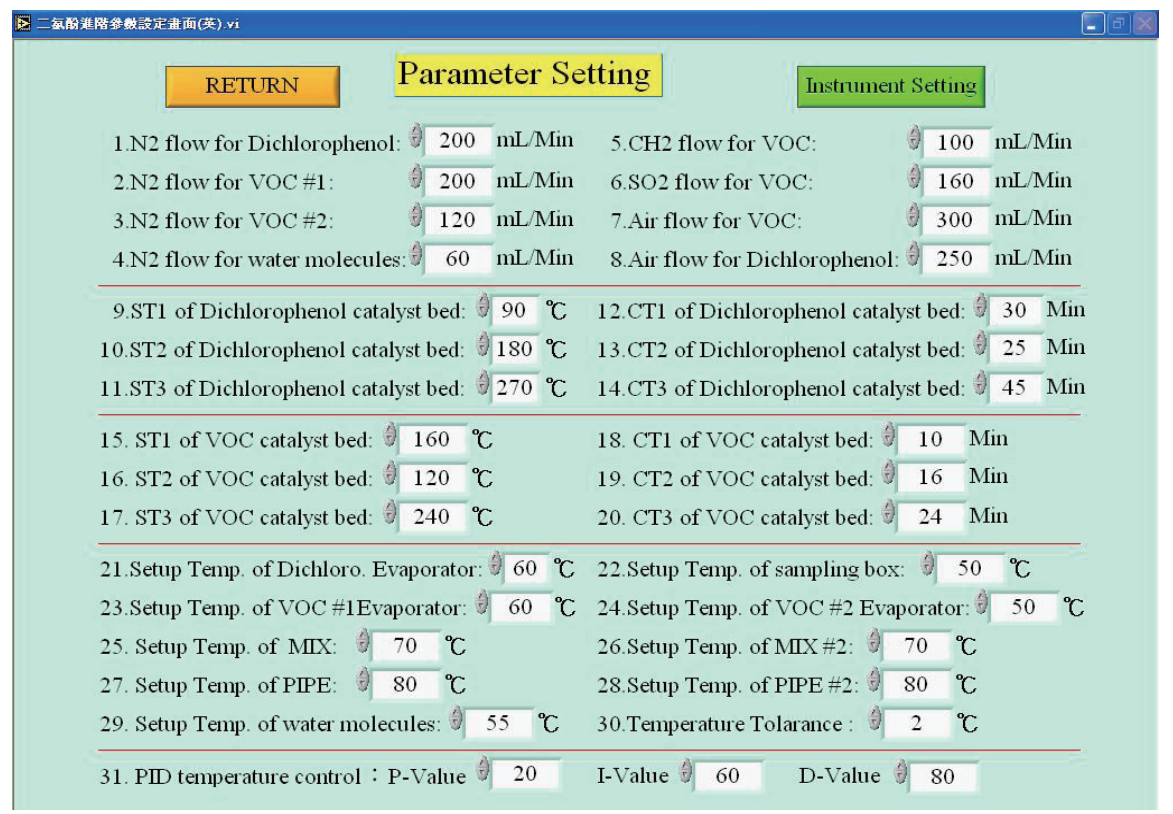

Fig. 3. (Color online) Monitoring parameter-setting

of the mixed gas. The three-stage temperature control parameters of the catalyst bed include the first-stage set temperature $\left(S T_{1}\right)$ and maintenance time $\left(C T_{1}\right)$, the second-stage set temperature $\left(S T_{2}\right)$ and maintenance time $\left(C T_{2}\right)$, and the third-stage set temperature $\left(S T_{3}\right)$ and maintenance time $\left(C T_{3}\right)$. Users can set the three-stage temperature control parameters to determine the temperature of the dichlorophenol or VOC catalyst bed changes. The three-stage temperature control parameters of the dichlorophenol catalyst bed can be seen in Fig. 3: $S T_{1}=90{ }^{\circ} \mathrm{C}, C T_{1}=15 \mathrm{~min}, S T_{2}=180{ }^{\circ} \mathrm{C}$, $C T_{2}=12 \mathrm{~min}$, and $S T_{3}=270{ }^{\circ} \mathrm{C}, C T_{3}=23 \mathrm{~min}$ (illustrated as mode 1). The corresponding temperature control curve is shown in Fig. 4(a). The three-stage temperature control parameters of the VOC catalyst bed are set as: $S T_{1}=160{ }^{\circ} \mathrm{C}, C T_{1}=10 \mathrm{~min}, S T_{2}=120{ }^{\circ} \mathrm{C}, C T_{2}=16 \mathrm{~min}$, $S T_{3}=240^{\circ} \mathrm{C}, C T_{3}=24 \mathrm{~min}$ (illustrated as mode 2). The corresponding temperature control curve is shown in Fig. 4(b). In this paper, we will discuss the differences between the catalytic reduction performance of dichlorophenol and VOCs in these two temperature control modes.

\section{Catalytic Reduction Process}

\subsection{Catalytic reduction workflow}

The system of the catalytic reduction process is shown in Fig. 5(a). The object to be treated (dichlorophenol or VOCs) can first be selected by the user, followed by three stages of operation. (I) Concentration blending stage: used to adjust the initial concentration of dichlorophenol or VOCs (Steps 1-3). (II) Catalytic reaction stage: carried out with a three-stage temperature control of the catalytic reduction reaction (Steps 4-6). (III) Emission analysis stage: exhaust the gas in the pipeline and carry out catalytic reduction performance analysis (Steps 7 and 8). Figure 6(b) shows the results of setting the switching knobs for dichlorophenol and VOCs. 


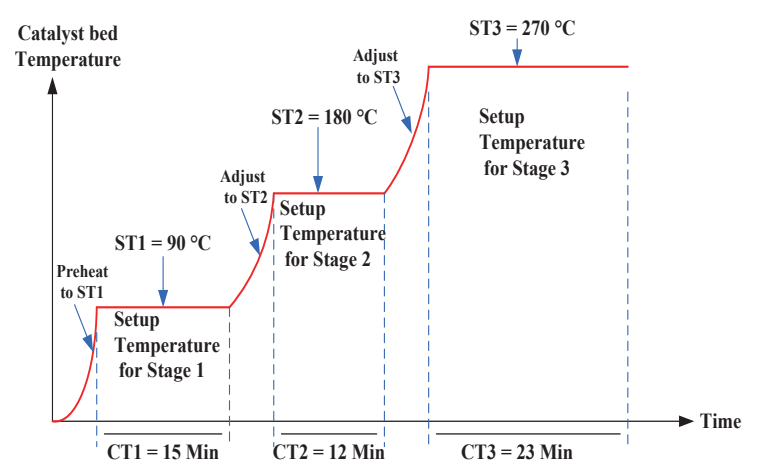

(a)

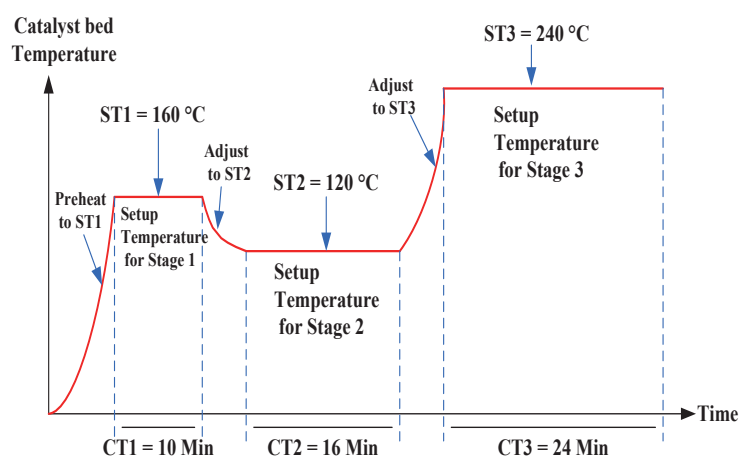

(b)

Fig. 4. (Color online) Three-stage temperature control curve of catalyst bed. (a) Mode 1 temperature control curve. (b) Mode 2 temperature control curve.

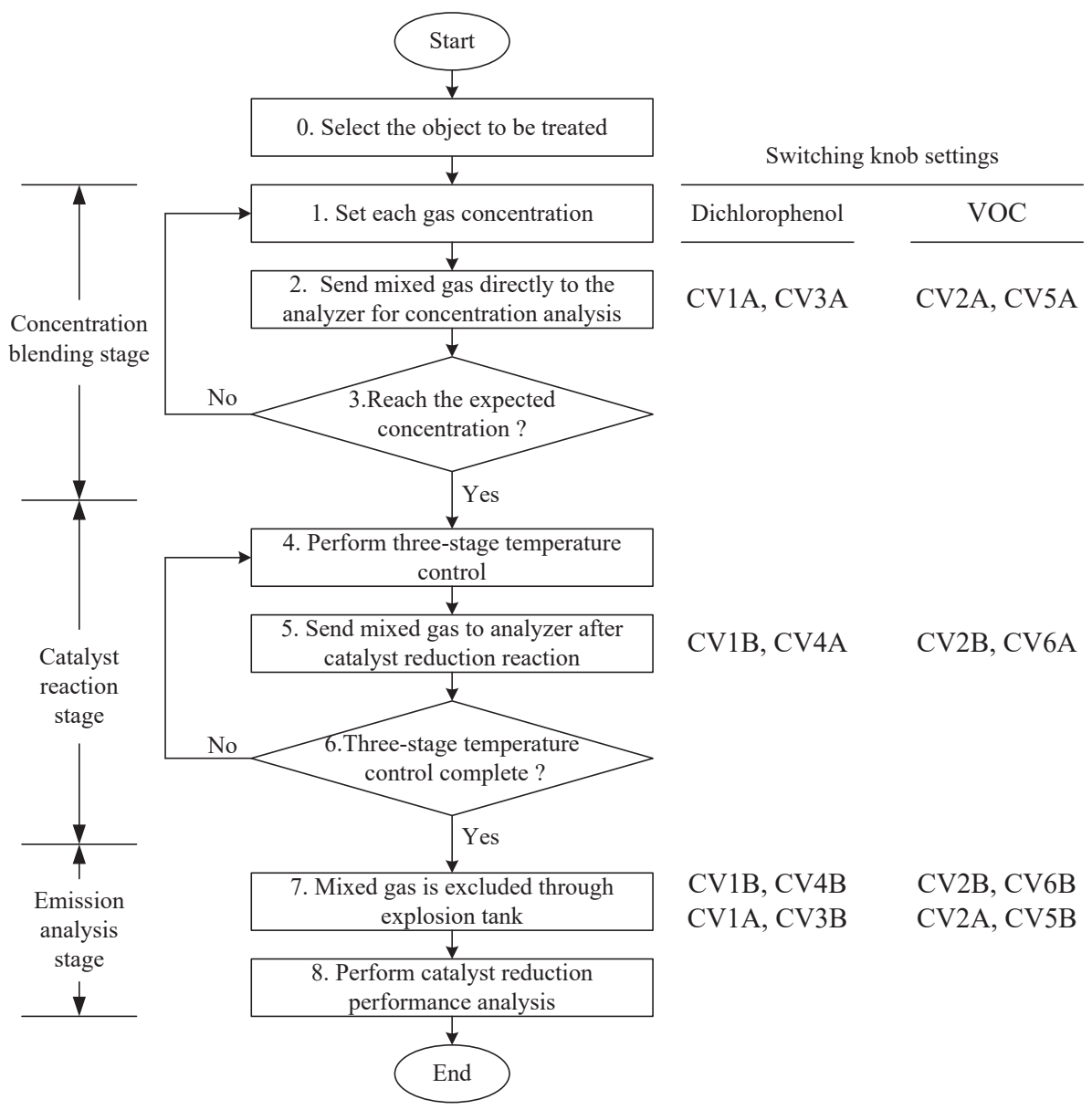

(a)

(b)

Fig. 5. Catalytic reduction operations. (a) Catalytic reduction workflow. (b) Setting of the switching knobs. 


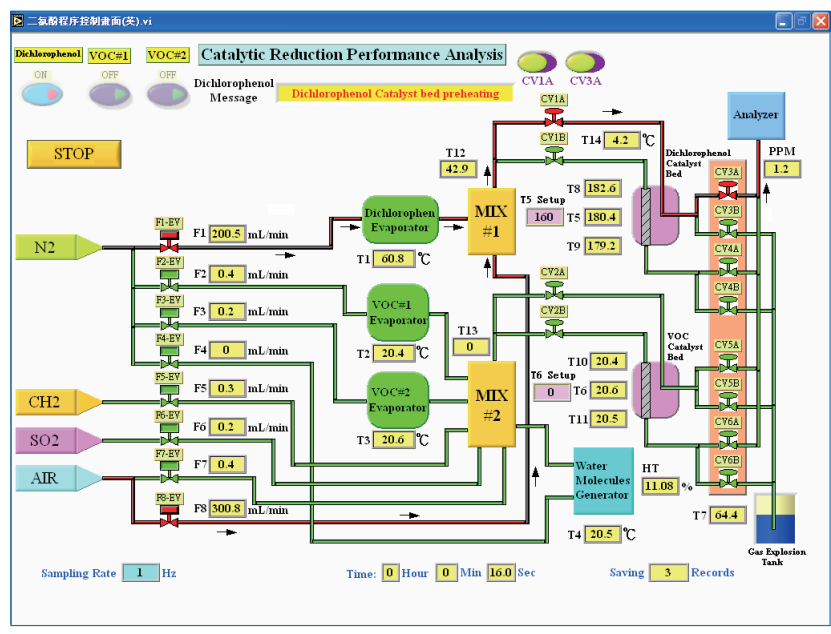

(a)

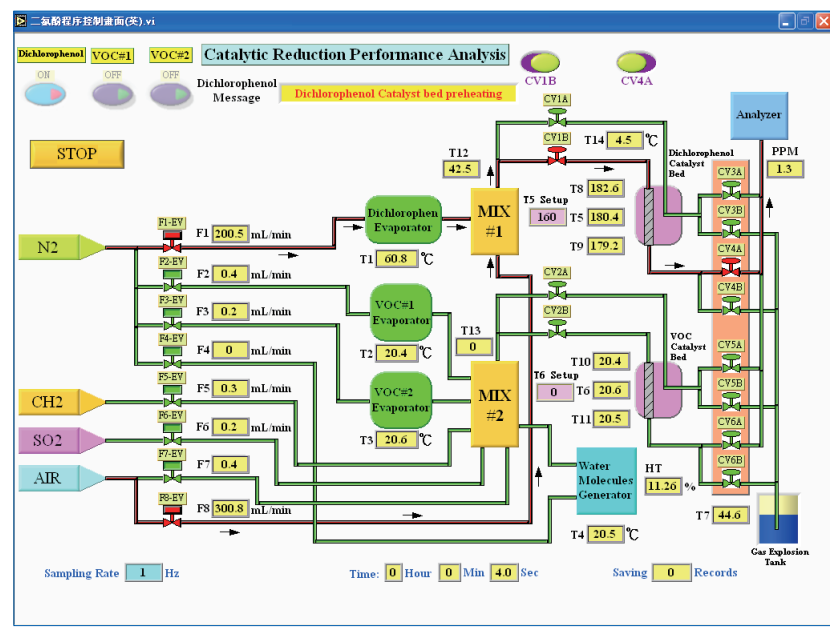

(b)

Fig. 6. (Color online) Dichlorophenol catalytic reduction reaction. (a) Dichlorophenol concentration blending procedure. (b) Dichlorophenol catalytic reduction reaction procedure.

\subsection{Dichlorophenal catalystic reduction process}

The user can select one of "Dichlorophenol", "VOC \#1" or "VOC \#2" in the upper left corner of the screen, as seen in Fig. 6, as the catalytic reduction target. Figure 6(a) shows the concentration distribution screen after selecting "Dichlorophenol", in which the red line (with the small arrow next to it) represents the open transmission path. In this deployment procedure, the system will control the flow rate of $\mathrm{N}_{2}$ and air in accordance with the monitoring parameters set by the user and also control the temperature of the dichlorophenol evaporator by heating. The evaporated dichlorophenol is transported by $\mathrm{N}_{2}$ gas to the first mixer MIX \#1, mixed with the participating air and sent directly to the analyzer through the sampling box for the analysis of the concentration of dichlorophenol (Step 2). If the concentration of dichlorophenol does not reach the desired initial concentration, the user can return to the parameter-setting screen to adjust the relevant gas flow parameter settings (Step 1) and perform Step 2 again with the concentration of the deployment process until the desired starting concentration is reached.

In the upper right part of the screen in Fig. 6(a), the two groups of switching buttons "CV1A/ $\mathrm{CV} 1 \mathrm{~B}$ " and "CV3A/CV3B" are given for the treatment of dichlorophenol. The former is used to switch the mixed gas through the catalyst bed. The current switch to CV1A indicates that the mixed gas has not passed through the catalyst bed. The latter is used to switch the mixed gas to the analyzer or to the gas chute. The present switch to CV3A indicates that the mixture is to be transferred to the analyzer for concentration analysis. The setting of the switching buttons at each stage of the catalytic reduction operation is as shown in Fig. 5(b).

When the analyzed concentration of dichlorophenol reaches the desired starting concentration, the second reaction stage can be carried out. The user first moves the switch from CV1A to CV1B, allowing the mixed gas to pass through the catalyst bed of dichlorophenol while the second set of switchover buttons are automatically changed to "CV4A/CV4B" for gas passing through 
the catalyst bed to the analyzer or the air slot, at which point it is switched to CV4A to deliver the mixed gas to the analyzer, as shown in Fig. 6(b). The user presses the "START" button to start the dichlorophenol reaction program. The system will perform the three-stage catalytic bed temperature control process automatically in accordance with the control parameters set in the screen shown in Fig. 3. In this control process, the system will use the P \& ID control method, ${ }^{(18)}$ in accordance with the temperature control curve shown in Fig. 4, and the intermediate temperature of the catalyst bed will be controlled. The inlet temperature and outlet temperature of the catalyst bed are automatically recorded, and the concentration of dichlorophenol is measured. The sampling frequency of the system is $1 \mathrm{~Hz}$, and the data archiving cycle is $20 \mathrm{~s} / \mathrm{cycle}$.

\subsection{VOC catalytic reduction process}

In the catalytic reduction operations, the VOCs must be mixed with a variety of ginseng gases, so the transmission line is more complex than that for dichlorophenol. Figure 7(a) shows the selection of the VOC \#1 concentration profile. The gas flows of $\mathrm{N}_{2}$ for $\mathrm{VOC} \# 1, \mathrm{CH}_{2}, \mathrm{SO}_{2}$, and air are controlled by the system according to the monitoring parameters set by the user. The VOC evaporator is heated to evaporate VOC, and the evaporated VOC is transported by $\mathrm{N}_{2}$ and sent to the second mixer, MIX \#2, to be mixed with $\mathrm{CH}_{2}, \mathrm{SO}_{2}$, and air. Then, the mixture is transferred to the water-molecule generator to mix with the water molecules brought out by $\mathrm{N}_{2}$ and sent directly to the analyzer through the sampling box for VOC concentration analysis (Step 2). If the VOC concentration does not reach the desired initial concentration, return to the settings of the relevant gas flow parameters (Step 1) in the screen shown in Fig. 3 and re-execute the concentration profile of Step 2 until the desired starting concentration is reached. In Step 2 of the VOC catalytic reduction operation, the switch buttons on the top right of the screen are set to CV2A and CV5A.

When the analyzed VOC concentration reaches the desired starting concentration, the catalytic reduction process can be activated in the second working stage. The user first moves the switching button from CV2A to CV2B, whereby the mixed gas passes through the VOC catalyst bed, and then moves the second switch to CV4A to deliver the mixed gas to the analyzer, as shown in Fig.

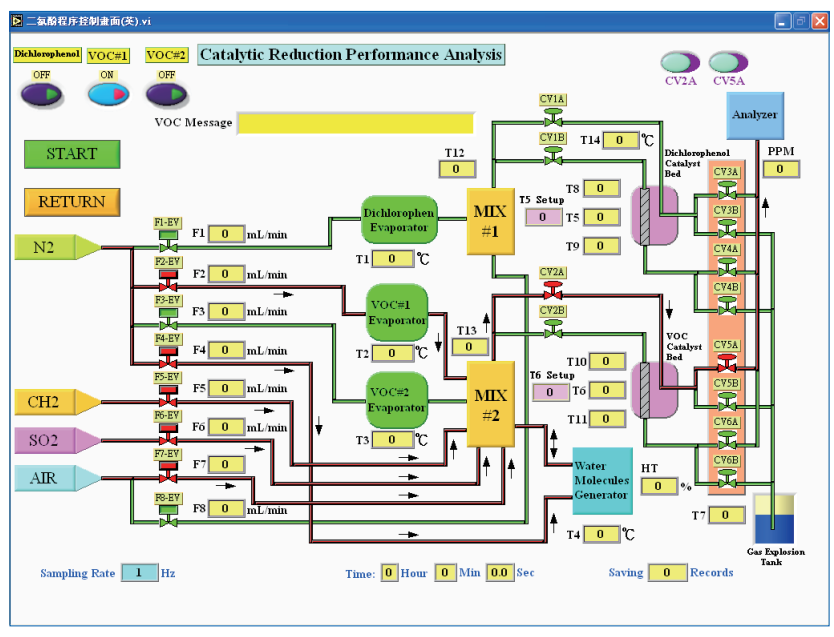

(a)

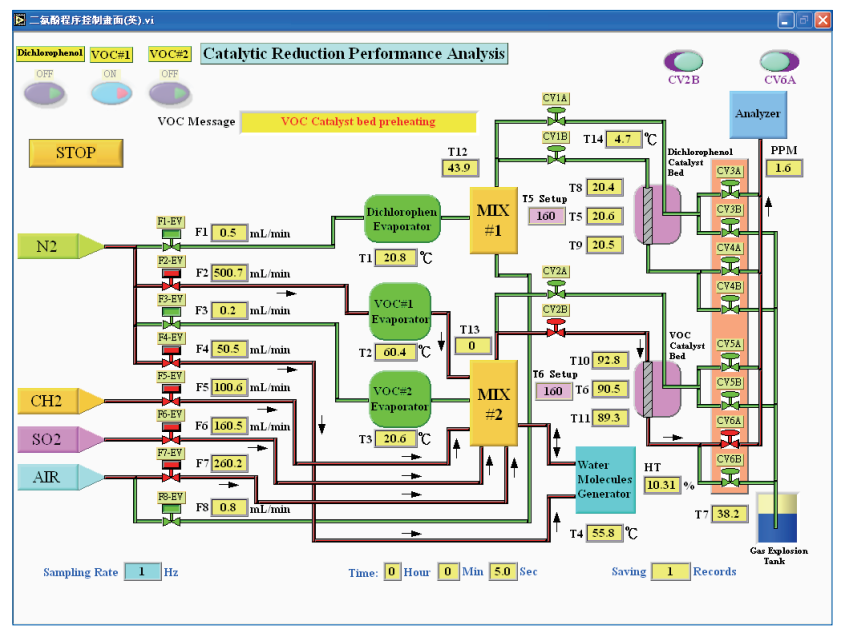

(b)

Fig. 7. (Color online) VOC catalytic reduction performance operations. (a) Procedure for starting VOC concentration. (b) VOC catalytic reduction reaction procedures. 
7(b). The user presses the "START" button to start the VOC catalytic reaction process. The system will perform the three-stage temperature control process automatically in accordance with the control parameters set in the screen shown in Fig. 3. During the VOC catalytic reaction process, the measured inlet temperature and outlet temperature of the catalyst bed and the analyzed VOC concentration are automatically recorded.

\subsection{Mixed gas adsorption and discharge}

After the completion of the catalytic reduction reaction operation, all of the dichlorophenol or VOC mixture remaining in the pipe must be removed before the next catalytic reaction can be carried out. The exhaust gas remaining in the pipe includes the gas retained in the transmission path with the catalyst bed and in the transmission path without the catalyst. The user can transfer the mixed gas left in the catalyst bed transmission path and the noncatalyst bed transmission path to the gas chute to be eliminated by medicine adsorption by setting the switching button at the upper right of the screen. For example, Fig. 8(a) shows the screen for the elimination procedure of the mixed gas left in the dichlorophenol catalyst bed transmission path. The two sets of switch buttons are set to CV1B and CV4B. To eliminate the dichlorophenol exhaust gas left in the noncatalyst bed transmission path, the switch buttons are set to CV1A and CV3B, respectively. Figure 8(b) shows the screen for the elimination procedure of the mixed gases left in the VOC catalyst bed transmission path. The two sets of switch buttons are set to CV2B and CV6B. To eliminate the VOC exhaust gas left in the noncatalyst bed transmission path, the switches are set to CV2A and CV5B, respectively.

\section{Catalytic Reduction Performance Analysis}

During the catalytic reaction monitoring process, the system automatically records the catalyst bed inlet temperature, outlet temperature, and concentration of dichlorophenol or VOCs. After the completion of the catalytic reduction reaction and discharge of exhaust gas retained in the pipeline, the user can use the recorded data to carry out the analysis of the catalytic reduction performance.

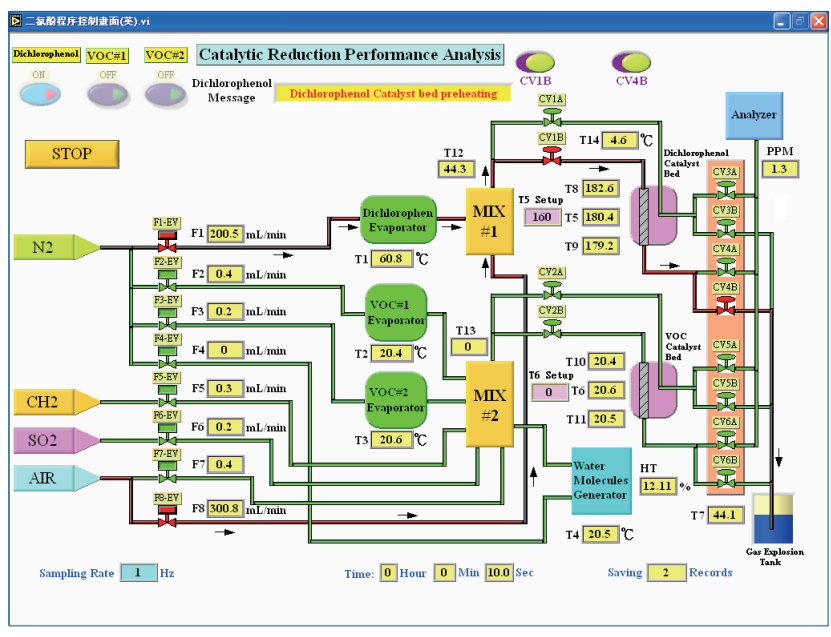

(a)

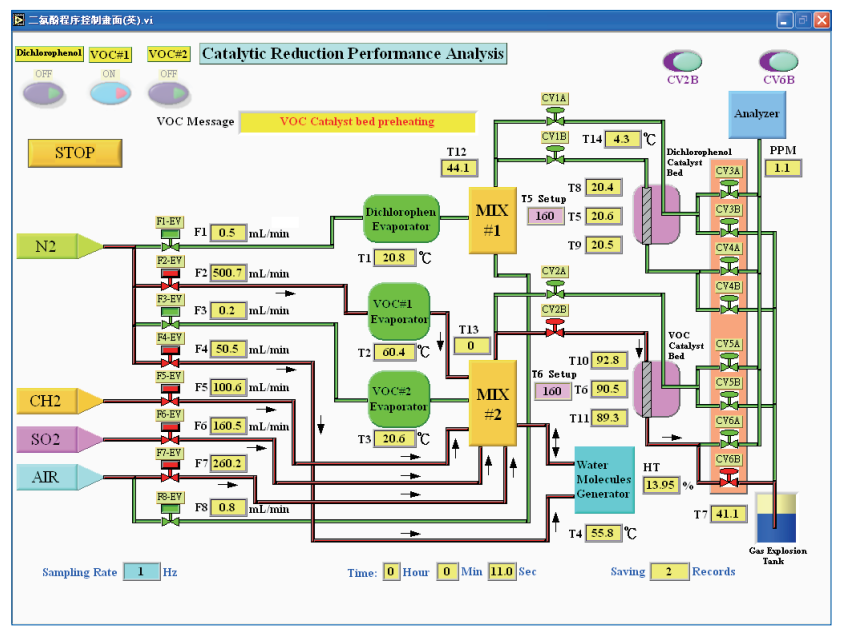

(b)

Fig. 8. (Color online) Mixed gas is removed through the gas chute. (a) Dichlorophenol mixed gas is transfered to the gas tank to be eliminated. (b) VOC mixed gas is sent to the gas tank to be eliminated. 
Figure 9(a) shows the system-generated catalytic performance curve for dichlorophenol under the first three-stage temperature control modes in Fig. 4(a), which includes inlet temperature, outlet temperature and analyzed concentration of dichlorophenol. The blue and green curves represent the inlet temperature and outlet temperature of the catalyst bed, respectively. The red curve shows the concentration of dichlorophenol measured in the analyzer. Figure 9(b) shows the use of the second three-stage temperature control mode in Fig. 4(b) to obtain the dichlorophenol catalytic reaction performance curve. The starting concentration of dichlorophenol in the tests shown in both Figs. 9(a) and 9(b) is $350 \mathrm{ppm}$. The comparative analysis of the curves shows that the amount of decrease in the red dichlorophenol concentration curve is greater in Fig. 9(a) than in Fig. 9(b). Also, the catalytic reduction performance of the Mode 1 temperature control curve is higher than that of the Mode 2 temperature control curve.

For these two temperature control modes, the changes in the inlet and outlet temperatures of the catalyst bed, the change in the decrease rate of the concentration of dichlorophenol, and the change in the decrease rate of the total concentration can be analyzed in detail from the recorded data. Tables 1 and 2 show the statistical results of the dichlorophenol catalyst efficiency analysis in

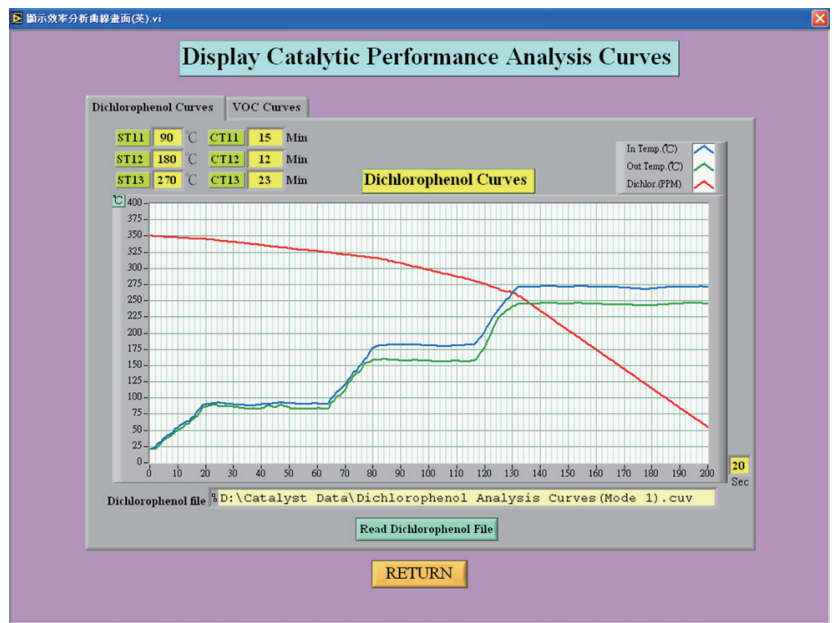

(a)

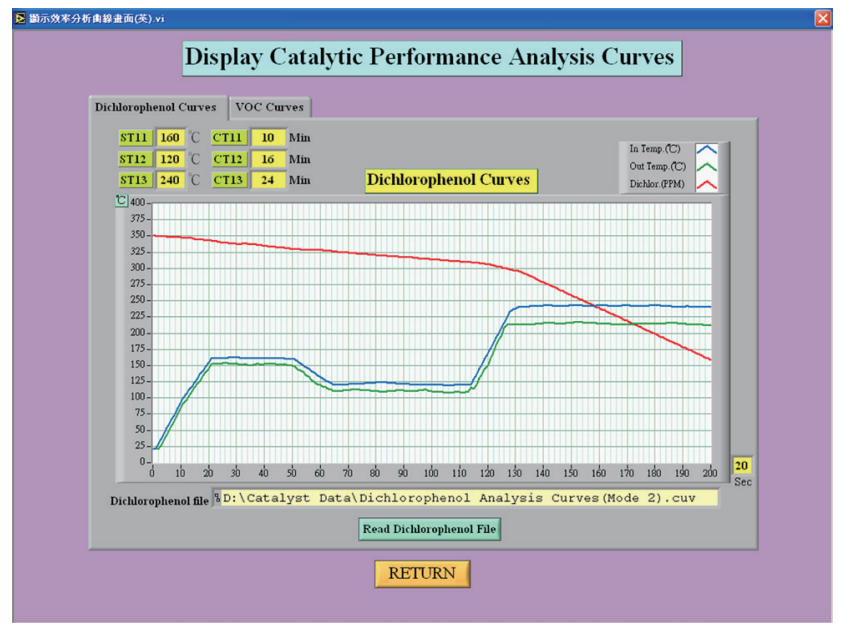

(b)

Fig. 9. (Color online) Dichlorophenol catalytic reaction performance analysis screen. (a) Dichlorophenol catalytic reaction curve in Mode 1. (b) Dichlorophenol catalytic reaction curve in Mode 2.

Table 1

Dichlorophenol catalytic reaction performance analysis results for Mode 1.

\begin{tabular}{lccccccccc}
\hline Stage & $C T_{i}(\mathrm{~min})$ & $T_{\text {aini }}\left({ }^{\circ} \mathrm{C}\right)$ & $T_{\text {aouti }}\left({ }^{\circ} \mathrm{C}\right)$ & $T_{\text {ai }}\left({ }^{\circ} \mathrm{C}\right)$ & $D C P_{\text {starti }}(\mathrm{ppm})$ & $D C P_{\text {endi }}(\mathrm{ppm})$ & $\Delta D C P_{i}(\mathrm{ppm})$ & $\Delta R_{\text {di }}(\%)$ & $R_{\text {di }}(\%)$ \\
\hline 1 & 15 & 89.52 & 85.38 & -4.14 & 345.26 & 334.48 & -10.78 & -3.08 & -0.21 \\
2 & 12 & 182.62 & 158.14 & -24.48 & 316.08 & 281.48 & -34.6 & -9.89 & -0.82 \\
3 & 23 & 271.69 & 245.58 & -26.11 & 258.17 & 51.78 & -206.39 & -58.97 & -2.56 \\
Sum & 50 & - & - & - & - & - & -251.77 & -71.93 & -1.44 \\
\hline
\end{tabular}

Table 2

Dichlorophenol catalytic reaction performance analysis results for Mode 2.

\begin{tabular}{lccccccccc}
\hline Stage & $C T_{i}(\mathrm{~min})$ & $T_{\text {aini }}\left({ }^{\circ} \mathrm{C}\right)$ & $T_{\text {aouti }}\left({ }^{\circ} \mathrm{C}\right)$ & $T_{a i}\left({ }^{\circ} \mathrm{C}\right)$ & $D C P_{\text {starti }}(\mathrm{ppm})$ & $D C P_{\text {endi }}(\mathrm{ppm})$ & $\Delta D C P_{i}(\mathrm{ppm})$ & $\Delta R_{\text {di }}(\%)$ & $R_{\text {di }}(\%)$ \\
\hline 1 & 10 & 161.46 & 152.25 & -9.21 & 342.89 & 329.38 & -13.51 & -3.86 & -0.39 \\
2 & 16 & 121.63 & 110.18 & -11.45 & 325.88 & 309.48 & -16.4 & -4.69 & -0.29 \\
3 & 24 & 241.69 & 212.54 & -29.15 & 297.8 & 156.78 & -141.02 & -40.29 & -1.68 \\
Sum & 50 & - & - & - & - & - & -170.93 & -48.84 & -0.98 \\
\hline
\end{tabular}


the first and second temperature control modes, respectively, where $C T_{i}$ is the $i$-phase elapsed time. $T_{\text {aini }}$ and $T_{\text {aouti }}$ are the average inlet temperature and average outlet temperature for the catalyst bed in stage $i$, respectively. $T_{a i}$ is the average temperature difference for phase $i\left(T_{a i}=T_{a o u t i}-T_{a i n i}\right)$. $D C P_{\text {starti }}$ is the initial dichlorophenol concentration for phase $i$, and $D C P_{\text {endi }}$ is the concentration at which it is terminated. $\triangle D C P_{i}$ is the change in the concentration of dichlorophenol in stage $i\left(\triangle D C P_{i}=D C P_{\text {endi }}-D C P_{\text {starti }}\right) . \quad R_{d i}$ represents the rate of decrease in the concentration of dichlorophenol at stage $i$, and $\Delta R_{d i}$ is the unit time decrease rate for this stage.

$$
\begin{gathered}
\Delta R_{d i}=\frac{\Delta D C P_{i}}{D C P_{\text {start }}} \times 100 \% \\
R_{d i}=\frac{\Delta R_{d i}}{C T_{i}} \times 100 \%
\end{gathered}
$$

Here, $D C P_{\text {start }}=350 \mathrm{ppm}$ is the starting concentration of dichlorophenol for this test, which is the same in both temperature control modes. In Tables 1 and 2, the values of the last line of the fields $C T_{i}, \Delta D C P_{i}, \Delta R_{d i}$, and $R_{d i}$ represent the total time of the three phases, the overall change in the concentration of dichlorophenol, the overall rate of decrease in the concentration of dichlorophenol, and the average rate of decline per unit time.

The analysis results in Tables 1 and 2 show that the higher the temperature of the reaction of the dichlorophenol catalyst at each stage, the greater the decrease rate of concentration per unit time, and the greater the decrease in the temperature of the catalyst bed inlet to the outlet temperature. That is, more heat will be consumed. This shows that the efficiency of the reaction of dichlorophenol catalyst is proportional to the consumption of thermal energy.

Figure 10(a) shows the use of the first three-stage temperature control mode in Fig. 4(a) to obtain the VOC catalytic reaction performance curve. Figure 10(b) shows the use of the second three-stage temperature control mode in Fig. 4(b) to obtain the VOC catalytic reaction performance curve. From the comparative analysis of the curves in Figs. 10(a) and 10(b), we see that the decrease in the red VOC concentration curve in Fig. 10(a) is greater than that in the VOC

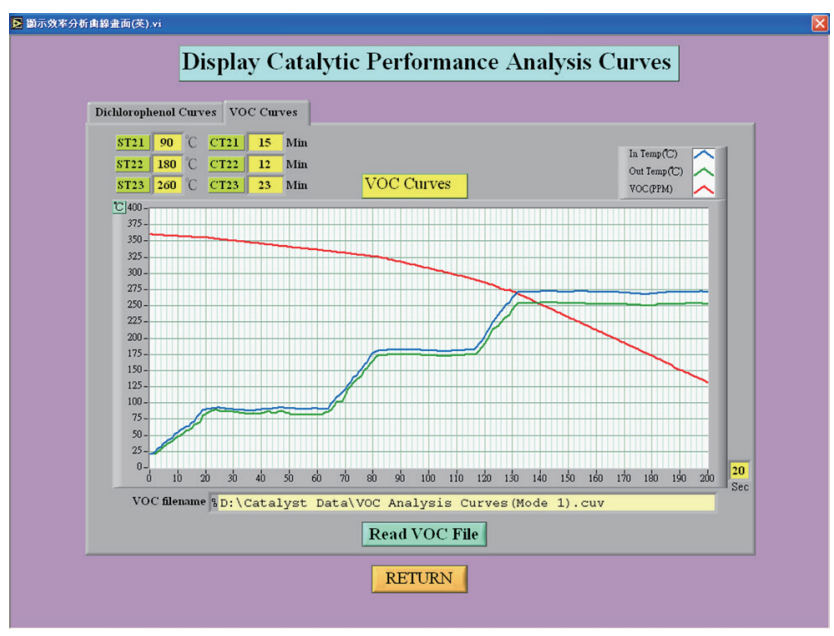

(a)

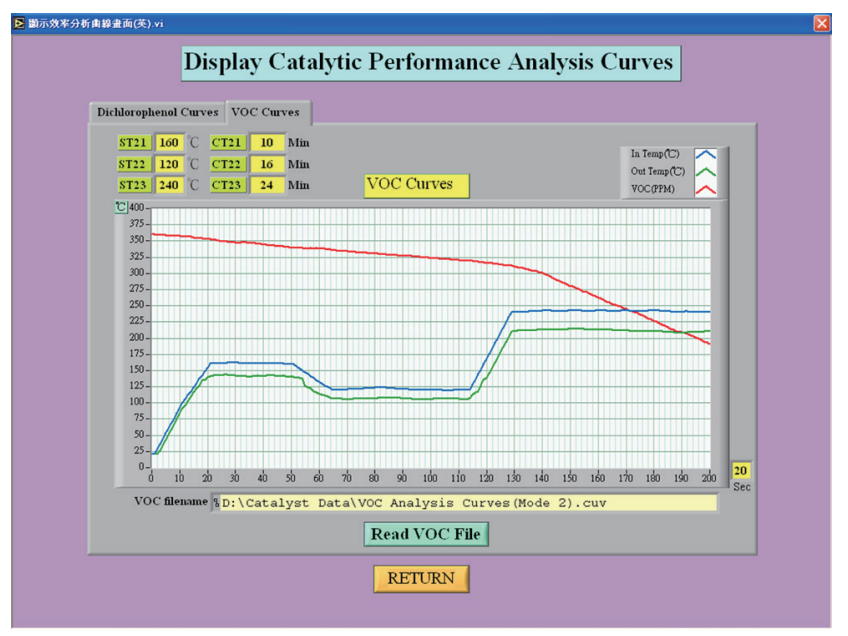

(b)

Fig. 10. (Color online) VOC catalytic reaction performance analysis. (a) Mode 1 VOC catalytic reaction analysis curve. (b) Mode 2 VOC catalytic reaction analysis curve. 
concentration curve in Fig. 10(b). The catalytic reduction performance of the Mode 1 temperature control curve is higher than that of the Mode 2 temperature control curve in the VOC catalytic reduction reaction. Since the system automatically records the catalytic response curve analysis, it can effectively provide the user with the ability to restore the benefits of catalytic analysis.

Tables 3 and 4 show the results of VOC catalyst efficiency analysis in the first and second temperature control modes, respectively. The symbols used are similar to those in Tables 1 and 2, where $V O C_{\text {starti }}$ is the initial VOC concentration for phase $i, V O C_{\text {endi }}$ is the concentration at termination, and $\triangle V O C_{i}$ is the change in the VOC concentration of the stage $\left(\Delta V O C_{i}=V O C_{\text {endi }}-V O C_{\text {starti }}\right) . \Delta R_{d i}$ represents the rate of decrease in the VOC concentration at stage $i$, and $R_{d i}$ is the unit time rate of decline at this stage.

$$
\begin{gathered}
\Delta R_{d i}=\frac{\Delta V O C_{i}}{V O C_{\text {start }}} \times 100 \% \\
R_{d i}=\frac{\Delta R_{d i}}{C T_{i}} \times 100 \%
\end{gathered}
$$

Here, $V O C_{\text {start }}=360 \mathrm{ppm}$ is the starting VOC concentration for this test and is the same in both temperature control modes. In Tables 3 and 4 , the values of the last line of the fields $C T_{i}, \triangle V O C_{i}$, $\Delta R_{d i}$, and $R_{d i}$ represent the total time of the three phases, the overall change in VOC concentration, the overall rate of decrease in VOC concentration, and the average unit time rate of decline. An analysis of the results in Tables 3 and 4 shows that the higher the temperature of the VOC catalytic reaction at each stage, the greater the decrease in concentration per unit time and the greater the decrease in the temperature from the catalyst bed inlet to the outlet temperature. That is, more heat will be consumed. This shows that the efficiency of the VOC catalytic reaction is also proportional to the heat consumption.

Table 3

VOC catalytic reaction performance analysis results for Mode 1.

\begin{tabular}{lccccccccc}
\hline Stage & $C T_{i}(\mathrm{~min})$ & $T_{\text {aini }}\left({ }^{\circ} \mathrm{C}\right)$ & $T_{\text {aouti }}\left({ }^{\circ} \mathrm{C}\right)$ & $T_{a i}\left({ }^{\circ} \mathrm{C}\right)$ & $V O C_{\text {starti }}(\mathrm{ppm})$ & $V O C_{\text {endi }}(\mathrm{ppm})$ & $\Delta O C_{i}(\mathrm{ppm}) \Delta R_{d i}(\%)$ & $R_{\text {di }}(\%)$ \\
\hline 1 & 15 & 89.82 & 84.72 & -5.1 & 355.36 & 336.58 & -18.78 & -5.22 & -0.35 \\
2 & 12 & 181.62 & 173.14 & -8.48 & 326.08 & 291.48 & -34.6 & -9.61 & -0.80 \\
3 & 23 & 272.7 & 253.58 & -19.12 & 268.17 & 129.78 & -138.39 & -38.44 & -1.67 \\
Sum & 50 & - & - & - & - & - & -191.77 & -53.27 & -1.07 \\
\hline
\end{tabular}

Table 4

VOC catalytic reaction performance analysis results for Mode 2.

\begin{tabular}{lccccccccc}
\hline Stage & $C T_{i}(\mathrm{~min})$ & $T_{\text {aini }}\left({ }^{\circ} \mathrm{C}\right)$ & $T_{\text {aouti }}\left({ }^{\circ} \mathrm{C}\right)$ & $T_{a i}\left({ }^{\circ} \mathrm{C}\right)$ & $V O C_{\text {starti }}(\mathrm{ppm})$ & $V O C_{\text {endi }}(\mathrm{ppm})$ & $\Delta O C_{i}(\mathrm{ppm})$ & $\Delta R_{d i}(\%)$ & $R_{d i}(\%)$ \\
\hline 1 & 10 & 160.54 & 142.39 & -18.15 & 352.82 & 339.36 & -13.46 & -3.74 & -0.37 \\
2 & 16 & 121.68 & 106.14 & -15.54 & 335.48 & 319.64 & -15.84 & -4.40 & -0.28 \\
3 & 24 & 240.47 & 211.58 & -28.89 & 311.8 & 188.78 & -123.02 & -34.17 & -1.42 \\
Sum & 50 & - & - & - & - & - & -152.32 & -42.31 & -0.85 \\
\hline
\end{tabular}




\section{Conclusions}

In this study, an automated monitoring system for the analysis of the reduction performance of dichlorophenol and VOC catalyst was developed. This system allows the user, by setting the monitoring parameters, to deploy the initial concentrations of dichlorophenol and VOCs and to define the different modes of the three stages of a temperature control curve. According to the parameters set, the system can automatically carry out three-stage temperature control of the catalytic reduction reaction operations. Users can also use the switch buttons provided by the system to control the transmission path of the mixed gases of dichlorophenols or VOCs in order to smoothly carry out the adjustment of concentration, catalytic reaction, and emission analysis. On the other hand, the system can automatically record the required catalytic reaction data during the reaction process of the catalyst, draw the corresponding catalytic reaction curve, and provide users with the analysis and research of the catalytic reduction benefit. In this study, we used two different modes of the three-stage temperature control curve to illustrate how to carry out the experiment on the reduction of dichlorophenol and VOCs in the two temperature control modes in this system, and compared and analyzed the difference in the reduction performance between the two modes.

\section{Acknowledgments}

This study was sponsored by the project of the Ministry of Science and Technology, R.O.C., project number: MOST 105-2221-E-344-004.

\section{References}

1 2- Dichlorophenol, Medical Encyclopedia, http://big5.wiki8.com/2.2Dlvbenfen_120942/(accessed June 2017).

2 Volatile Organic Compounds (VOC), Science Online, http://highscope.ch.ntu.edu.tw/wordpress/?p=4290 (accessed June 2017).

3 T. Boningari and P. G. Smirniotis: Curr. Opin. Chem. Eng. 13 (2016) 133.

4 J. P. Chen and R. T. Yang: J. Catal. 139 (1993) 277.

5 X. S. Deng: Final report of Nation Science Council Research Project, NSC87-EPA-P-006-003 (1998).

6 H. Wang, Z. Qu, S. Dong, H. Xie, and C. Tang: Env. Sci. Technol. 50 (2016) 13511.

7 G. Gao, J. W. Shi, Z. Y. Fan, C. Gao, and C. M. Niu: Chem. Eng. J. 325 (2017) 91.

8 R. T. Guo, M. Y. Li, P. Sun, S. M. Liu, S. X. Wang, W. G. Pan, and X. Sun: RSC Adv. 7 (2017) 19912.

9 Y. Li, Y. Wan, Y. P. Li, S. H. Zhan, Q. X. Guan, and Y. Tian: ACS Appl. Mater. Interfaces 8 (2016) 5224.

10 T. Y. Lee and H. L. Bai: AIMS Environ. Sci. 3 (2016) 261.

11 G. Gao, J. W. Shi, C. Liu, C. Gao, Z. Y. Fan, and C. M. Niu: Appl. Surf. Sci. 411 (2017) 338.

12 P. Sun, R. T. Guo, S. M. Liu, S. X. Wang, W. G. Pan, M. Y. Li, S. W. Liu, J. Liu, and X. Sun: J. Mol. Catal. 433 (2017) 224.

13 T. H. Vuong, J. Radnik, J. Rabeah, U. Bentrup, M. Schneider, H. Atia, U. Armbruster, W. Grückner, and A. Brückner: ACS Catal. 7 (2017) 1693.

14 C. Shao, X. Liu, D. Meng, Q. Xu, Y. Guo, Yun Guo, W. C. Zhan, and G. Lu: RSC Adv. 6 (2016) 66169.

15 F. Y. Gao, X. L. Tang, H. H. Yi, J. Y. Li, S. Z. Zhao, J. G. Wang, and C. L. Li: Chem. Eng. J. 317 (2017) 20.

16 J. Liu, X. Y. Li, Q. D. Zhao, J. Ke, H. N. Xiao, X. J. Lv, S. M. Liu, M. Tadé, and S. B. Wang: Appl. Catal., B 200 (2017) 297.

17 S. Z. Xie: Graphical Programming Language LabVIEW (Chuan Hwa Book Co., Taipei, 2013).

18 K. H. Ang, G. Chong, and Y. Li: IEEE Trans. Control Syst. Technol. 13 (2005) 559. 


\section{About the Authors}

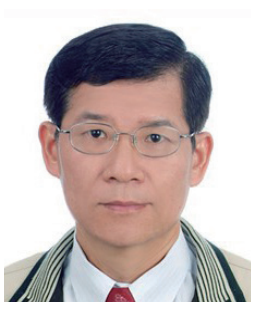

Ming-Sen Hu received his B.S. degree from National Chau-Tung University, Taiwan, in 1984 and his M.S. and Ph.D. degrees from the National Taiwan University, in 1987 and 1993, respectively. Since 1994, he has been an associate professor at the Air Force Institute of Technology. His research interests are in automatic measurement, digital control systems, and software engineering.

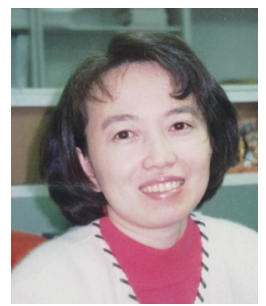

Liang-Hsiu Chen received her B.A. degree from the Chinese Culture University, Taiwan, in 1983 and her M.A. degree from the Monterey Institute of International Studies, U.S.A., in 1993. From 1993 to 1997, she was a systems coordinator at the Ministry of Science and Technology, R.O.C. Since 1998, she has been a lecturer at Chang Jung Christian University. 